\title{
Visual angle and the word superiority effect
}

\author{
DEAN G. PURCELL, KEITH E. STANOVICH, and AMOS SPECTOR \\ Oakland University, Rochester, Michigan 48063
}

\begin{abstract}
Two experiments are reported in which a word superiority effect is obtained under conditions where a fixed set of alternatives are employed with positional certainty as to the critical letter, trial type (word or nonword) is mixed, and the subject is told to fixate the position of the critical letter. A third experiment employed the same methodology except for the fact that the stimuli subtended a larger retinal angle. No word superiority effect was observed in the third experiment. It is suggested that the visual angle of the stimulus display is a crucial factor in experiments on the word superiority effect.
\end{abstract}

Within cognitive psychology, one problem that continues to generate much empirical work and heated theoretical discussion is that of identifying the perceptual unit involved in word recognition. Most current models of the recognition process assume that a visual stimulus is recognized by its physical features matching a set of features stored in long-term memory. The perceptual unit problem can thus be stated in the form of a question. What segment of a visually presented word is represented by a feature list in long-term memory? Obvious candidates for perceptual units in word recognition are letters, spelling patterns, syllables, and whole words.

Actually, the perceptual unit problem has a long history in experimental psychology. Cattell (1886) found that subjects could identify two four-letter words at a tachistoscopic exposure duration where only three to four unrelated letters were correctly identified. These results were interpreted as indicating that words were "recognized as wholes" (i.e., the word was the perceptual unit when it was presented) in contrast to the situation when unrelated letters were presented (where presumably the letter was the perceptual unit). Since processing each perceptual unit takes some amount of time, stimulus configurations with less units should be processed faster, thus accounting for Cattell's word superiority effect. However, subsequent research (Miller, Bruner, \& Postman, 1954) indicated that it was simply not necessary to hypothesize perceptual units larger than the letter in order to explain the experimental results. It seemed that word superiority effects in tachistoscopic recognition could be accounted for by either guessing based on sequential redundancy or short-term memory limitations involved in the whole report procedure.

This situation was changed drastically when Reicher

This research was supported in part by an Oakland University research grant. The authors thank Sarkice Nedder for his assistance in data collection. Reprint requests should be sent to Keith E: Stanovich, Department of Psychology, Oakland University, Rochester, Michigan 48063. Amos Spector is now with the Unit of Military Psychology, Israeli Defense Forces, Military P.O. Box 2719, Z,H,L, Isracl.
(1969) provided the first demonstration of a word superiority effect in an experiment where sequential redundancy and short-term memory factors were controlled. Reicher's postcue procedure, which is now well known, involved presenting two letter alternatives at a particular letter position subsequent to stimulus exposure. The letter alternatives were chosen so that both would form words when a word was presented and form nonwords when a nonword was presented. Thus, guessing based on the knowledge that the stimulus was a word could not improve performance. In addition, the partial-report forced-choice response procedure limited the influence of short-term memory factors. Reicher's observation that performance on word trials was superior to that on nonword trials led him to revive the word as a perceptual unit hypothesis. Strictly, the Reicher result does not necessarily imply that words are the perceptual units. Both spelling pattern units (Gibson, Pick. Osser, \& Hammond, 1962) and syllablelike units (Spoehr \& Smith, 1973) have been used to explain the superiority of words over nonwords in tachistoscopic recognition. Following Smith and Haviland (1972), explanations that account for word superiority effects by hypothesizing perceptual units of larger than letter size will be termed unitization models.

An additional result observed by Reicher (1969) seemed to require for its explanation assumptions additional to unitization. Reicher observed performance on word trials to exceed even that on trials where single letters were presented. Kahneman (1973, pp. 85-85) hypothesized that recognition units of various sizes are processed in parallel when words are presented. Correct detection could then result from a feature match at more than one level. This explanation is a variant of the "more features" model discussed by Wheeler (1970). He hypothesized that words actually contained more information in the form of supraletter features than individual letters. If the supraletter features (e.g., the roundness of $\mathrm{CO}$ or the squareness of $\mathrm{NI}$ ) are processed in parallel with individual letter features, the subject has more information available relevant to the critical discrimination when words are presented. Both the 
parallel recognition model of Kahneman (1973) and the more features model of Wheeler (1970) should be considered unitization models since they involve recognition units larger than the letter. Although the models do assume that units of letter size are involved, these are processed in parallel with units larger than the letter.

Unitization models, according to the distinction introduced by Atkinson and Shiffrin (1968), account for word superiority effects by hypothesizing the presence of a particular structural feature in the processing system (visual feature units of larger than letter size stored in a long-term memory). Structural features are the permanent features of memory that do not vary from one situation to another. Recent evidence, however, has led investigators to question whether an account of the word superiority effect in terms of structural features is necessary. Massaro (1973; Thompson \& Massaro, 1973) has argued that the Reicher (1969) postcue procedure does not adequately control for redundancy. If the subject synthesizes the critical letter before the alternatives appear, then redundancy can facilitate the perception of letters in words at the time of recognition. Reicher's procedure controls only for redundancy operating at a guessing stage after recognition has taken place. Thompson and Massaro (1973) presented evidence indicating that the critical letter is synthesized prior to the onset of the alternatives. They observed no effect of the similarity of the letter alternatives when the postcue procedure was employed. However, in a second experiment using a fixed set of word and letter alternatives (C, G, P, R, ACE, AGE, APE, ARE) that the subject knew in advance, a significant effect of visual similarity was observed. In addition, the fixed stimulus sets resulted in a letter superiority effect. This result is consistent with other research that finds the word superiority effect to disappear when the subject has prior knowledge of the alternatives (Bjork \& Estes, 1973; Estes, Bjork, \& Skaar, 1974).

Massaro (1973) replicated the letter superiority effect using the fixed stimulus sets of Thompson and Massaro (1973). In addition, Massaro (1973) found no difference in recognition accuracy between the word set ACE, AGE, APE, ARE and the nonword set VCH, VGH, VPH, VRH. Massaro (1973) argued that the pattern of results on the word superiority effect could be explained by hypothesizing an inference process that worked at the time of stimulus recognition on letter-size units. The model works as follows. Suppose the word WORD is presented in the Reicher postcue paradigm and the subject extracts sufficient visual features to reduce the alternatives to $\mathrm{V}$ or $\mathrm{W}, \mathrm{C}$ or $\mathrm{O}, \mathrm{R}$ or $\mathrm{P}$, and $\mathrm{D}$ or $\mathrm{B}$ across the four positions. If the subject expected visual configurations to spell a word, he would synthesize WORD, and then when given the alternatives $D$ and $K$ for the last position, correctly choose $D$. On singleletter trials, the subject might synthesize D or B. If the original extracted features are integrated into a complete visual percept, then chance performance will result when the subject synthesizes a B and is shown the alternatives $D$ and $K$. Evidence that the subject is unaware of which visual features have been extracted once a verbal classification has been made comes from studies showing that subjects are often unable to report the case of a series of letters even when the letters have been correctly identified (Coltheart \& Freeman, 1974; McClelland, 1976).

The inference model described above explains the word superiority effect observed in the Reicher postcue paradigm and the lack of such an effect when the restricted sets employed by Massaro (1973) are used. In the latter situation, a bias to infer a word from incomplete information will not improve performance on word trials, since the four stimulus alternatives, which all form words, are known to the subject in advance. Since the letter is assumed to be the perceptual unit, and the members of the word set differ from each other in exactly the same features as the members of the letter set, performance across the two stimulus types should be equivalent. More precisely, one might expect the results actually observed by Massaro (1973), that performance would be inferior on word trials due to lateral masking. In fact, when the nonword set VCH, VGH, VPH, and VRH is used, performance does not differ across stimulus type.

Estes (1975a, 1975b) has suggested that decision and interpretation processes in short-term memory subsequent to feature extraction are responsible for word superiority effects. Specifically, it is hypothesized that information from each letter location is encoded separatly, but that there is some uncertainty as to which features were extracted from which spatial positions in the array. The constraints within words serve to increase the probability that the subject will attribute the extracted features to their correct spatial positions. Enhanced performance on word stimuli occurs because on some trials the subject will have extracted enough information from nontarget locations for perfect identification, but will still be in doubt about the target location. The nontarget letters that have been identified will help the subject decide which of the remaining features came from which spatial location. Estes' positional uncertainty hypothesis posits that word superiority effects result from the decision process in short-term memory that follows feature extraction.

Some investigators have speculated that features other than those from letter units are extracted in word recognition, but that the detection of such features depends on a subject-controlled attention allocation process. Carr, Lehmkuhle, Kottas, Astor-Stetson, and Arnold (1976) found a word superiority effect with a fixed set of stimuli using a blocked-trial design. They argued that blocking induces the subject to optimally allocate attention across the stimulus display, and thus enables him to encode the additional information 
available in words. The results from a study by Johnston and McClelland (1974) seem consistent with this conjecture. They observed that for nonword strings instructing the subject to fixate the location in which the critical letter would appear enhanced performance relative to a condition in which the subject was told to allocate his attention over the entire array. In contrast, when the stimuli were words, instructions to fixate the critical letter position actually decreased performance relative to the condition where the subject was told to distribute his attention. Johnston and McClelland (1974) argued that these results support the contention that the word superiority effect is dependent on an attention allocation process that is under the subject's control. It is thus possible that subjects do have supraletter features of words stored in memory. However, unlike features from letter units, they are not automatically extracted, but instead are activated only when the subject allocates attention to them.

The above discussion suggests that it might be useful to distinguich three positions regarding the role of supraletter features in word processing. One denies the existence of such features and accounts for the word superiority effect by hypothesizing an inference process that operates on letter-size units (Massaro, 1973). Another position admits the possibility of supraletter features but claims that their processing is dependent on the subject's adopting the proper attentional set (Carr et al., 1976). The third position, that supraletter features are extracted automatically (i.e., independent of subject strategies), appears to have no support in the literature on tachistoscopic word recognition. It will be argued here that there exists a fourth possibility, specifically, that supraletter features are extracted automatically only under certain conditions having to do with the visual characteristics of the stimulus display.

One variable that has varied unsytematically in the studies reviewed above is the retinal angle subtended by the stimulus display. This angle has ranged from a low of $.6 \mathrm{deg}$ (Spector \& Purcell, 1977) to a high of $4.5 \mathrm{deg}$ (Estes, 1975b). Considering only those studies that have compared words to nonwords and that meet Massaro's (1973) criterion of prior knowledge of alternatives, we find the word superiority effect only in studies that employed stimuli that subtended $1.0 \mathrm{deg}$ or less. Thompson and Massaro (1973) did use a visual angle of less than $1.0 \mathrm{deg}$, but the crucial comparison in their study was between words and single letters. Those studies that compared words to nonwords and failed to find the word superiority effect used stimuli subtending 3.33 deg (Massaro, 1973) and 4.5 deg (Bjork \& Estes, 1973; Estes et al., 1974). Those studies that found evidence of a word superiority effect employed stimuli subtending .6 deg (Spector \& Purcell, 1977) and $1.0 \mathrm{deg}$ (Carr et al., 1976; Smith \& Haviland, 1972). In general the evidence regarding stimulus retinal angle indicates a possibility that this variable is involved in the word superiority effect.
The effect of the retinal angle of the stimulus, or the retinal locus of individual letters in the stimulus, has not been assessed in studies of the word superiority effect. However there is ample evidence that retinal locus can influence the perception of a visual stimulus. Visual acuity is markedly reduced by small changes in distance from the center of the fovea (see Riggs, 1965; Westheimer, 1970). Reaction time to visual target letters increases by about $100 \mathrm{msec}$ when the retinal locus of presentation is changed from the point of fixation $(0.0 \mathrm{deg})$ to $3.0 \mathrm{deg}$ peripheral to the point of fixation (Eriksen \& Schultz, 1977).

There is also evidence that retinal position plays a role in the phenomenon of visual masking. A patterned backward mask has been shown to be necessary to obtain the word superiority effect (Johnston \& McClelland, 1973). Although retinal position effects have largely been ignored in studies of the word superiority effect, large effects of this variable have been demonstrated in the masking paradigm. Matthews (1973) found up to $50 \%$ reduction in a forward masking condition and a $10 \%$ reduction in a backward masking condition by changing the locus of stimulus presentation mask condition from $0.0 \mathrm{deg}$ to $1.75 \mathrm{deg}$. Purcell and Stewart (1975) investigated backward masking of both white targets and black targets. They found up to a $20 \%$ reduction in target report for both target types when retinal locus was changed from 0.0 to $1.67 \mathrm{deg}$. Merikle, Coltheart, and Lowe (1971) found a 50\% reduction in target report, under backward masking, with a change in retinal locus from about 0.0 to $1.75 \mathrm{deg}$. In a control experiment with no mask, they found a $40 \%$ decrease over the same range. Although the above is not an exhaustive review of retinal position effects in the masking literature, it does indicate the possibility of fairly strong retinal position effects in studies of the word superiority effect.

Word superiority effects in fixed-alternative experiments have tended to be correlated with the size of the stimuli employed. In a series of studies that have not found the effect (Bjork \& Estes, 1973; Estes et al., 1974), the retinal locus of the center of the outside letters was $1.88 \mathrm{deg}$. In the Massaro (1973) study, the retinal locus of the center of the outside letters was $1.35 \mathrm{deg}$. The ranges of retinal eccentricity used in the above studies are great enough to produce differential masking effects. In contrast, studies where word superiority effects have been observed under fixed-alternative conditions have used stimuli of a much smaller size. Spector and Purcell (1977) employed stimuli that fell a maximum of $.3 \mathrm{deg}$ from center. Carr et al. (1976) and Smith and Haviland (1972) employed stimuli that fell a maximum of $.5 \mathrm{deg}$ from center. Thus, it is possible that the size of the stimulus display is a potentially important variable in experiments on the word superiority effect. Perhaps supraletter features are only automatically extracted when the component letters are close together in the visual field. 


\section{EXPERIMENT 1}

Experiment 1 attempted to eliminate the operation of subject strategies and inference processes by using the stimulus sets of Massaro (1973), which control for redundancy and positional uncertainty, presenting words and nonwords in a mixed sequence, and instructing the subject to attend to the middle letter of the display. The latter two controls were designed to disrupt the attention allocation process discussed by Carr et al. (1976) and Johnston and McClelland (1974). However, in contrast to previous research, visual displays were employed that subtended less than $1.0 \mathrm{deg}$ of visual angle. Thus, if supraletter features are automatically extracted from stimuli subtending small visual angles, a word superiority effect should still be obtained in this experiment, even though inference and attention-allocation strategies were eliminated by the experimental design.

\section{Method}

Subjects. The subjects were 10 volunteer psychology students recruited on the Oakland University campus.

Materials and Apparatus. The words ACE, AGE, APE, and ARE, and the nonwords VCH, VGH, VPH, and VRH made up the stimulus set. These stimuli were typed on $6 \times 9$ in. $(15.2 \times 22.9 \mathrm{~cm})$ cards, using IBM Pica Prestige type. All were typed with uppercase letters. The stimuli were presented via an Iconix tachistoscope at a viewing distance of $88.9 \mathrm{~cm}$. Each three-letter stimulus subtended $.53 \mathrm{deg}$. The mask was made up of overprinted Xs and Os and was .32 deg high by $.94 \mathrm{deg}$ wide covering the stimulus area. A single black fixation point was located in a separate field and was centered $.2 \mathrm{deg}$ below the center letter in the stimulus. The stimulus field was set at about $65.00 \mathrm{~cd} / \mathrm{m}^{2}$, the mask field at about $40.44 \mathrm{~cd} / \mathrm{m}^{2}$ and the continuously illuminated fixation field at about $10.00 \mathrm{~cd} / \mathrm{m}^{2}$. The target field duration was set at $30 \mathrm{msec}$ and the mask field at $100 \mathrm{msec}$. The stimulus onset asynchrony (SOA) separating the onset of the target from the onset of the mask was adjusted individually for each subject.

Procedure. Subjects were instructed to fixate the black fixation point and were informed they would be shown groups of three letters and that they should report only the middle letter. Subjects were told that the center letter would be C, G, $\mathrm{P}$, or $\mathrm{R}$, but they were not told that some letter groups were words and some were nonwords. They were instructed to guess if they were not sure what letter they had seen. Subjects initiated the target and mask sequence at a ready signal from the experimenter. Each subject was tested individually in a single $1-\mathrm{h}$ session. Prior to data collection, 72 practice trials (equal number of words and nonwords) were given each subject to familiarize him with the response set and to determine SOA that would yield between $70 \%$ and $75 \%$ correct averaged across words and nonwords. The subjects were not informed that the first 72 trials were practice. After the practice trials, 144 experimental trials were completed with all eight stimuli presented an equal number of times in random order. If during the experimental trials, the subject's performance level shifted from the 70\%-75\% level, the SOA was adjusted so as to bring him back to that performance level. Adjustments were made only on predetermined trials such that an equal number of words and nonwords were presented at a given SOA.

\section{Results and Discussion}

For each subject, the percentage of correct responses was computed for each of the two stimulus types (word. nonword). Across subjects, the mean percent correct for words and nonwords was $71.1 \%$ and $63.6 \%$, respectively. An analysis of variance with stimulus type as a within-subjects factor indicated that the effect of stimulus type was significant $[F(1,9)=15.81, p<.005]$. Additionally, it should be noted that 9 out of 10 subjects displayed superior performance on word trials and one subject performed equally on the two stimulus types.

These results provide the first demonstration of a word superiority effect in an experiment using prior knowledge of alternatives, mixed presentation, positional certainty of the critical letter, and instructions to the subjects to fixate the critical letter. These controls were designed to eliminate the influence of expectancy, attention-allocational, and inferential processes. Before proceeding to a fuller discussion of the results, two further experiments are presented that explore the boundary conditions of the effect.

\section{EXPERIMENT 2}

Experiment 2 was designed to further restrict the use of inferential processes by limiting the number of letter alternatives to two. All of the controls employed in Experiment 1 were also present.

\section{Method}

The subjects were 15 volunteer psychology students recruited on the Oakland University campus. The words APE and ACE, and the nonwords VPH and VCH made up the stimulus set. All other apparatus was the same as in Experiment 1. Subjects completed 72 practice trials and 72 experimental with the four stimuli presented in random order with equal proability.

\section{Results and Discussion}

For each subject, the percentage of correct responses was computed for each of the two stimulus types. Across subjects, the mean percent correct for words and nonwords was $73.8 \%$ and $64.4 \%$, respectively. An analysis of variance with stimulus type as a withinsubjects factor indicated that the effect of stimulus type was significant $[F(1,14)=9.98, p<.01]$. Thirteen of the 15 subjects displayed superior performance on the word trials. Thus, Experiment 2 has replicated the result of a word superiority effect with prior knowledge of alternatives, mixed presentation, positional certainty, and instructions to fixate the critical letter.

\section{EXPERIMENT 3}

It was suggested in the introduction that previous failures to observe the word superiority effect might be due to the utilization of a stimulus size that renders the context letters functionally useless. Experiments 1 and 2 demonstrated word superiority effects with stimulus strings of a much smaller visual angle than that used in previous research. In Experiment 3, this notion was 
tested directly by utilizing a larger stimulus display. With respect to all the other controls previously discussed, Experiment 3 was identical to Experiment 2.

\section{Method}

Subjects. The subjects were 15 volunteer psychology students recruited on the Oakland University campus.

Procedure. Experiment 3 was the same as Experiment 2 in all respects, except for the size of the stimuli and mask. Each three letter stimulus subtended $2.11 \mathrm{deg}$. The height of each individual letter was about $.4 \mathrm{deg}$ and tite width was $.23 \mathrm{deg}$. Accordingly, the $A$ and $E$ and the $V$ and $H$ were centered on points about $.89 \mathrm{deg}$ right and left of the center of the centra! letter $C$ or $P$. The mask was made up of overlapping $N s$ and $D$ s. Each individual letter in the mask was about the same size as letters in the three-letter stimulus. The mask itself was $2.5 \mathrm{deg}$ high by $3.0 \mathrm{deg}$ wide.

\section{Results and Discussion}

For each subject, the percentage of correct responses was computed for each of the two stimulus types. Across subjects, the mean percent correct for words and nonwords was $68.7 \%$ and $67.6 \%$, respectively. An analysis of variance with stimulus type as a withinsubjects factor indicated that this difference was not statistically significant $[F(1,14)=.23]$. Eight subjects displayed superior performance on word trials, six sub. jects displayed superior performance on the nonword trials, and one subject showed no difference.

The data from Experiments 2 and 3 were subjected to a two-way analysis of variance, with stimulus type as a within-subjects factor and experiment (2 vs. 3) as a between-subjects factor. The results of this analysis yielded a significant stimulus type effect $\{\mathrm{F}(1,28)=7.73$, $\mathrm{p}<.01]$ and a nonsignificant effect of experiment $[F(1,28)=.09]$. More importantly, the Stimulus Type by Experiment interaction was statistically significant $[\mathrm{F}(1,28)=4.81, \mathrm{p}<.05]$.

\section{GENERAL DISCUSSION}

Experiments 1 and 2 have shown the word superiority effect to be a more robust phenomenon than previously thought. It appears that blocking of the stimulus types. absence of prior knowledge of alternatives, consciously allocating attention over the visual field, or positional uncertainty are not necessary in order for a word superiority effect to be obtained. The generality of earlier studies that have implied that the effect was dependent on one of these variables is thus called into question. The results of Experiment 3 suggested an explanation of why some previous researchers have failed to find the effect. Specifically, many researchers have used a display size that served to attenuate any effect that context might have. That is, either through acuity loss of peripherally located context or through the breaking up of perceptual units by separating the contexi from the critical item, a large visual angle may render nonfunctional a unit that is available for use in recognition when the size of the stimuli is smaller. Experiment 3 supported this interpretation. The conditions of Experiment 3 were identical to those of Experiment 2 except for the size of the stimuli. Statistical analyses indicated that a significant word superiority effect occurred in Experiment 2, but not in Experiment 3 . This conclusion was given additional support by the presence of the significant experiment by stimulus type interaction.

In summary, the word superioity effects found in Experiments $i$ and 2 seem not to be due to subjectcoritrolled strategies or inferential processes. It now seems more parsirnonious to assume that units of larger than letter sice (pernaps the supraletter features of Wheeler, 1970) are processed in parallel with letter units (Kahneman, 1973) and thus provide additional information relevant to any letter discrimination in the word, and that this mechanism can lead to a word superiority effeci when inferential processes are controlled. However. it appears that this structural feature of the processing system is operative only when the visual display subtends a fairly small visual angle. Thus, when the stimulus size is such that an automatic feature match to these supraletter units cannot be made, word superiority effects disappear, as in Experiment 3. However. it is possible that under conditions of relatively large visual argle, the subject can employ control processes to attempt to compensate for the decreased availability of the larger than letter-size features. For example, it is possible that the allocation of attention effect for words observed by Johnston and McClelland (1974) is only necessary when the stimulus array is arranged in such a way as to disrupt the automatic activation of units of larger than letter size. The visual angle used by Johnston and McClelland (1974) was $1.90 \mathrm{deg}$ compared with the $.53 \mathrm{deg}$ employed in Experiments 1 and 2. Furthermore, their large visual angle resulted partially from the fact that they inserted a half space between their letters, a manipulation that could interfere with the pickup of supraletter features. The argument being made here is that with such visual displays it is likely that the subject does bring to bear control processes of the type demonstrated by Johnston and McClelland (1974). However, such processes are necessary only when the size of the visual display prevents a feature match from occurring at levels more complex than the individual letter. Matching on the basis of such features probably does occur with stimuli of a smaller visual angle.

\section{REFERENCES}

Atkinson. R. C., \& Shiffrin, R. M. Human memory: A proposed system and its control processes. In K. W. Spence \& J. T, Spence (Eds.), The psychology of learning and motivation: Advances in research and theory (Vol. 2). New York: Academic Press, 1968.

BjorK, E. L., \& Estes, W. K. Letter identification in relation to linguistic context and masking conditions. Memory \& Cognition, 1973, 1. 217.223. 
Carr, T. H., Lehmuuhle, S. W., Kottas, B., Astor-Stetson, E. C., \& ARnold, D. Target position and practice in the identification of letters in varying contexts: A word superiority effect. Perception \& Psychophysics, 1976, 19, 412-416.

Cattell, J. M. The time it takes to see and name objects. Mind, 1886, 11, 63-65.

Coltheart, M., \& Freeman, R. Case alternation impairs word identification. Bulletin of the Psychonomic Society, 1974, 3, 102-104.

Eriksen, C. W., \& Schultz, D. W. Retinal locus and acuity in visual information processing. Bulletin of the Psychonomic Society, 1977, 9, 81-84.

Estes, W. K. Memory, perception, and decision in letter identification. In R. L. Solso (Ed.), Information processing and cognition: The Loyola symposium. Hillsdale, N.J: Lawrence Erlbaum, 1975. (a)

Estes, W. K. The locus of inferential and perceptual processes in letter identification. Joumal of Experimental Psychology: General, 1975, 104, 122-145. (b)

Estes, W. K., Bjork, E. L., \& SkaAR, E. Detection of single letters and letters in words with changing vs unchanging mask characters. Bulletin of the Psychonomic Society, 1974, 3, 201-203.

Gibson, E. J., Pick, A., Osser, H., \& Hammond, M. The role of grapheme-phoneme correspondence in the perception of words. American Journal of Psychology, 1962, 75, 554-570.

Johnston, J. C., \& McClelland, J. L. Visual factors in word perception. Perception \& Psychophysics, 1973, 14, $365-370$.

Johnston, J. C., \& McClelland, J. L. Perception of letters in words: Seek not and ye shall find. Science, .1974, 184, 1192-1194.

Kahneman, D. Attention and effort. Englewood Cliffs, N.J: Prentice-Hall, 1973.

Massaro, D. W. Perception of letters, words, and nonwords. Journal of Experimental Psychology, 1973, 100, 349-353.

Matthews, M. L. Locus of presentation and the selective masking effect. Canadian Journal of Psychology, 1973, 27, 343-349.
McClelland, J. L. Preliminary letter identification in the perception of words and nonwords. Journal of Experimental Psychology: Human Perception and Performance, 1976, 2. 80-91.

Merikle, P. M., Coltheart, M., \& Lowe, D. G. On the selective effects of a patterned masking stimulus. Canadian Journal of Psychology, 1971, 25, 264-279.

Miller, G. A., Bruner, J. S., \& Postman, L. Familiarity of letter sequences and tachistoscopic identification. Journal of General Psychology, 1954, 50, 129-139.

Purcell, D. G., \& Stewart, A. L. A comparison of white and black carpets under conditions of masking by a patterned stimulus. Bulletin of the Psychonomic Society, $1975,6,13-15$.

Reicher, G. M. Perceptual recognition as a function of meaningfulness of stimulus materials. Journal of Experimental Psychology, 1969, 81, 275-280.

RIgGs, L. A. Visual acuity. In C. H. Graham (Ed.), Vision and visual perception. New York: Wiley, 1965.

Smith, E. E., \& Haviland, S. E. Why words are perceived more accurately than nonwords. Journal of Experimental Psychology, 1972, 92, 59-64.

Spector, A., \& Purcell, D. G. The word superiority effect: A comparison between restricted and unrestricted alternative set. Perception \& Psychophysics, 1977, 21, 323-328.

Spoehr, K. T., \& Smith, E. E. The role of syllables in perceptual processing. Cognitive Psychology, 1973, 5, 71-89.

Thompson, M. C., \& Massaro, D. W. Visual information and redundancy in reading. Journal of Experimental Psychology, 1973, 98, 49-54.

WestheIMER, G. Image quality in the human eye. Optica Acta, 1970, 17, 641-658.

WheEler, D. D. Processes in word recognition. Cognitive Psychology, 1970, 1, 59-85.

(Received for publication August 9, 1977; accepted October 31, 1977.) 